\title{
COMMENTARY
}

\section{Citrulline: just a biomarker or a conditionally essential amino acid and a pharmaconutrient in critically ill patients?}

\author{
Luc Cynober ${ }^{* 1,2}$ \\ See related research by Ware et al., http://ccforum.com/content/17/1/R10
}

\begin{abstract}
Low plasma citrulline levels have been associated with a reduction of functional gut mass in various clinical situations. In critically ill patients, citrulline variations are tricky to interpret because of sepsis, vascular abnormalities, and multiple organ failure. In the previous issue of Critical Care, Ware and colleagues made an important contribution by demonstrating that very low citrulline levels are associated with acute respiratory distress syndrome. This association may be due to a decrease in citrulline availability or citrulline overconsumption for nitric oxide synthesis but also may result from an arginine deficiency syndrome. In any case, the results of this study reinforce the rationale for a study of citrulline supplementation in critically ill patients.
\end{abstract}

In the previous issue of Critical Care, Ware and colleagues [1] showed that citrulline (CIT) plasma levels are extremely low in critically ill patients with sepsis and significantly lower in patients complicated with acute respiratory distress syndrome (ARDS). Thus, this study brings the new and important information that CIT depletion may be related to morbid events. In addition, these data form a strong rationale for CIT supplementation in intensive care unit (ICU) patients with sepsis.

For a long time, CIT was considered just a 'garbage' amino acid because it is not included in proteins and is known only as an intermediary in the urea cycle. However, some early classic studies suggested that CIT

\footnotetext{
*Correspondence: solange.ngon@cch.aphp.fr

'Department of Clinical Chemistry, Cochin and Hôtel-Dieu Hospitals, AP-HP,

27 rue du Fbg St Jacques, 75014 Paris, France

Full list of author information is available at the end of the article
}

had a unique metabolism and that its deficiency might be harmful (reviewed recently in [2]). The fact that CIT is almost absent from food (with the notable exception of watermelon) and is synthesized solely by the gut at the whole body level led Crenn and colleagues [3] to hypothesize, and then prove, that CIT plasma level is a reliable marker of intestinal functional mass. A number of studies worldwide confirmed the reliability of CIT as a biomarker of intestinal function in a number of pathological settings (reviewed recently in [4]).

CIT plasma levels appear to be extremely low in all patients. This contrasts with the results of other recent studies $[5,6]$ performed in critically ill patients in which CIT levels appear more variable at admission and in the course of the disease. The gut function was considered (existence of gut failure or not) in these two latter studies but was not considered in the article by Ware and colleagues [1], and so it is difficult to explain clearly where hypoCIT comes from. Surprisingly, the results show no difference between patients with renal failure and those without it. The same was observed in another study [7]. In the case of renal failure, CIT levels should be increased [8]. This indicates that an unknown covariable (for example, gut failure) tends to decrease CIT. Another point of complexity is the type of ICU patients. In the surgical ICU, in most cases, time 0 is the surgical operation. In the medical ICU (as in the present study), the time between acutization of the disease (for example, acute respiratory failure in chronic obstructive pulmonary disease) and admission in the ICU may range widely. Therefore, the metabolic status of patients may be widely variable from one to another, and this introduces a heterogeneity within the study and when comparing the results with those from similar work.

The authors hypothesize that CIT is overmetabolized, in particular in patients with ARDS, and they may be right, but alternatively we can hypothesize that low CIT is a result of an arginine (ARG) deficiency syndrome [9]. The authors claim that ARG levels (range of 9.6 to 
$40.0 \mu \mathrm{mol} / \mathrm{L}$ ) were within the normal ranges, but it is unclear how these normal ranges were obtained. Normal ranges have been established on a similar Hitachi (Tokyo, Japan) analyzer [10] and are $80 \pm 20 \mu \mathrm{mol} / \mathrm{L}$ (mean \pm standard deviation). Other methods [11] provide similar normal values. Most patients in the article by Ware and colleagues appear, on the basis of this consensus, actually to be severely deficient in ARG, and, of course, this fact may radically change the interpretation of the data.

The problem of the ARG/CIT balance is a tricky one and falls into the category of the famous chicken-or-egg dilemma. For example, Ware and colleagues [1] present CIT as the substrate for nitric oxide synthase (NOS). This is right, but through recycling via argininosuccinate and ARG (reactions mediated by argininosuccinate synthase and lyase $[\mathrm{ASS}+\mathrm{ASL}])$. Hence, in the reaction mediated by NOS, ARG is the substrate and CIT is the product. Plenty of data give the ARG $\rightarrow$ CIT and the CIT $\rightarrow$ ARG fluxes at the whole body level [12] or at the organ level by using stable isotopes and arterio-venous differences. I do not know of any data that establish, at the cellular level, that ARG is a better precursor of nitric oxide (NO) than CIT or vice versa. In addition, in vitro data suggest that the ability of ARG or CIT to generate NO in macrophages (which play a key role in sepsis and ARDS) is co-regulated by glutamine [13], whose availability is decreased in sepsis. In the case of sepsis, we cannot safely speculate, because, on the one hand, it is true that ASS + ASL and NOS channel CIT, but on the other hand, the ARG transporter CAT2 (cationic amino acid transporter 2) is also connected to inducible NOS, and both are overexpressed in sepsis [14]. The absence of any difference in ARG levels between patients with ARDS and those without it apparently supports the authors' view that the key is CIT, not ARG. However, the absence of any correlation between amino acids and NO end-products (that is, nitrate + nitrate) supports the idea that the answer is in the lung, not in the plasma, and that - in the absence of measurements with stable isotopes, arterio-venous difference, and measurements in the bronchoalveolar fluid - all these considerations are just a matter of speculation. As all these determinations are invasive and not necessary feasible in the ICU, I suggest two avenues of research in order to progress in this field. The first one is mechanistic and uses an experimental model of sepsis with ARDS. The second is pragmatic: as suggested by Ware and colleagues [1], it is to supplement patients with CIT at admission in the ICU and look at ARDS behavior.

In conclusion, we must avoid overspeculating from these results, but the great merit of Ware and colleagues [1] is to establish, on the basis of a large number of ICU patients, that plasma CIT level measured at admission may be a biomarker of ARDS. In addition, the results of this study, in conjunction with those of three recent experimental studies in sepsis conditions [15-17], offer a strong rationale for an interventional study in ICU patients.

\section{Abbreviations}

ARDS, acute respiratory distress syndrome; ARG, arginine; ASL, argininosuccinate lyase; ASS, argininosuccinate synthase; CIT, citrulline; ICU, intensive care unit; NO, nitric oxide; NOS, nitric oxide synthase.

\section{Competing interests}

The author receives honorarium from Nestlé Clinical Nutrition and shares patents with Paris Descartes University. The author is a shareholder in Citrage (Creteil, France).

\section{Author details}

'Department of Clinical Chemistry, Cochin and Hôtel-Dieu Hospitals, AP-HP, 27 rue du Fbg St Jacques, 75014 Paris, France. ${ }^{2}$ Department of Experimental, Metabolic and Clinical Biology, Laboratory of Biological Nutrition EA 4466, Faculty of Pharmacy, Paris Descartes University, 4 avenue de I'Observatoire, 75006 Paris, France.

Published: 11 March 2013

\section{References}

1. Ware LB, Magarik JA, Wickersham N, Cunningham G, Rice TW, Christman BW, Wheeler AP, Bernard GR, Summar ML: Low plasma citrulline levels are associated with acute respiratory distress syndrome in patients with severe sepsis. Crit Care 2013, 17:R10.

2. Cynober L, Moinard C, De Bandt JP: The 2009 ESPEN Sir David Cuthbertson. Citrulline: a new major signaling molecule or just another player in the pharmaconutrition game? Clin Nutr 2010, 29:545-551.

3. Crenn P, Coudray-Lucas C, Thuillier F, Cynober L, Messing B: Postabsorptive plasma citrulline concentration is a marker of absorptive enterocyte mass and intestinal failure in humans. Gastroenterology 2000, 119:1496-1505.

4. Crenn P, Hanachi M, Neveux N, Cynober L: [Circulating citrulline levels: a biomarker for intestinal functionality assessment]. Ann Biol Clin 2011, 69:513-521. Article in French.

5. Grimaldi D, Guivarch E, Neveux N, Fichet J, Pène F, Marx JS, Chiche JD, Cynober L, Mira JP, Cariou A: Markers of intestinal injury are associated with endotoxemia in successfully resuscitated patients. Resuscitation 2013, 84:60-65.

6. Piton G, Manzon C, Monnet E, Cypriani B, Barbot O, Navellou JC, Carbonnel F, Capellier G: Plasma citrulline kinetics and prognostic value in critically ill patients. Intensive Care Med 2010, 36:702-706.

7. Noordally SO, Sohawon S, Semlali H, Michely D, Devriendt J, Gottignies P: Is there a correlation between circulating levels of citrulline and intestinal dysfunction in the critically ill? Nutr Clin Pract 2012, 27:527-532.

8. Curis E, Nicolis I, Moinard C, Osowska S, Zerrouk N, Bénazeth S, Cynober L: Almost all about cittrulline in mammals. Amino Acids 2005, 29:177-205.

9. Popovic PJ, Zeh HJ, Ochoa JB: Arginine and immunity. J Nutr 2007, 137:1681S-1686S.

10. Le Boucher J, Charret C, Coudray-Lucas C, Giboudeau J, Cynober L: Amino acid determination in biological fluids by automated ion-exchange chromatography: performance of Hitachi L-8500A. Clin Chem 1997. 43:1421-1428.

11. Alteheld B, Stehle P, Fürst P: Measurement of amino acid concentrations in biological fluids and tissues using reversed-phase HPLC-based methods. In Metabolic and Therapeutic Aspects of Amino Acids in Clinical Nutrition. Edited by Cynober L. Boca Raton, FL, USA: CRC Press; 2004:29-44.

12. Kao CC, Bandi V, Guntupalli KK, Wu M, Castillo L, Jahoor F: Arginine, citrulline and nitric oxide metabolism in sepsis. Clin Sci 2009, 117:23-30.

13. Bryk J, Ochoa JB, Correia MITD, Munera-Seeley V, Popovic PJ: Effect of citrulline and glutamine on nitric oxide production in RAW 264.7 cells in an arginine-depleted environment. JPEN 2008, 32:377-383.

14. Cynober LA: Plasma amino acid levels with a note on membrane transport: characteristics, regulation, and metabolic significance. Nutrition 2002, 18:761-766

15. Wijnands KA, Vink H, Briedé JJ, van Faassen EE, Lamers WH, Buurman WA, Poeze M: Citrulline a more suitable substrate than arginine to restore NO production and the microcirculation during endotoxemia. PLoS One 2012, 
7:e37439.

16. Batista MA, Nicoli JR, Martins Fdos S, Machado JA, Arantes RM, Quirino IE, Correia MI, Cardoso VN: Pretreatment with citrulline improves gut barrier after intestinal obstruction in mice. JPEN 2012, 36:69-76.

17. Asgeirsson T, Zhang S, Nunoo R, Mascarenas C, Dujovny N, Luchtefeld M, Cavey GS, Senagore A: Citrulline: a potential immunomodulator in septis. Surgery 2011, 150:744-751. doi:10.1186/cc12534

Cite this article as: Cynober L: Citrulline: just a biomarker or a conditionally essential amino acid and a pharmaconutrient in critically ill patients? Critical Care 2013, 17:122 